\title{
ИСТОРИЧЕСКАЯ ПАМЯТЬ В ПРОЦЕССАХ ПОЛИТИЧЕСКОЙ МОДЕРНИЗАЦИИ ПОЛИЭТНИЧНОГО СОЦИУМА ${ }^{1}$
}

\section{HISTORICAL MEMORY IN THE PROCESSES OF POLITICAL MODERNIZATION OF MULTI-ETHNIC SOCIETY}

\section{K. Vodenko \\ O. Labadze \\ M. Tihonovskaya}

Summary: The article analyzes the role of historical memory in the processes of political modernization in a modern multi-ethnic society. It is concluded that the processes of political modernization should be guided by the cultural and national traditions of peoples, it is necessary to use their potential in integrating and mobilizing society for further development. To create a favorable social and investment climate in the region, modern political institutions are needed, whose activities are aimed at identifying the causes of the crisis state of society, determining the strategy of socio-economic development of territories, and searching for resources that can ensure the introduction of innovations that meet the needs of society.

Keywords: historical memory, political institutions, political modernization, multi-ethnic society, society.
Воденко Константин Викторович

Д.ф.н., профессор, Южно-Российский государственный политехнический университет

(НПИ) имени М.М. Платова, г. Новочеркасск, vodenkok@mail.ru

Лабадзе Олеся Евгеньевна

К.с.н., дочент, Южно-Российский государственный политехнический университет (НПИ) имени М.М. Платова, г. Новочеркасск, efimowa.olesya@yandex.ru Тихоновскова Мария Петровна М.н.с., Южно-Российский государственный политехнический университет (НПИ) имени М.М. Платова, г. Новочеркасск, tikhonovskova.maria@yandex.ru

Аннотация: В статье анализируется роль исторической памяти в процессах политической модернизации в условиях современного полиэтничного социума. Делается вывод о том, что процессы политической модернизации должны ориентироваться на культурно-национальные традиции народов, необходимо использовать их потенциал в интеграции и мобилизации общества для дальнейшего развития. Для создания благоприятного социально-инвестиционного климата в регионе необходимы современные политические институты, деятельность которых направлена выявление причин кризисного состояния социума, определение стратегии социально-экономического развития территорий, поиск ресурсов, способных обеспечить внедрение инноваций, отвечающих потребностям жизни общества.

Ключевые слова: историческая память, политические институты, политическая модернизация, полиэтнический социум, общество.

которой будет зависеть ее конкурентоспособность в мировой системе. Это актуализирует проблему поиска оптимального проекта модернизации российского полиэтничного общества, который бы одновременно учитывал как лучшие образцы зарубежного опыта модернизации западных стран, так и культурно-исторические особенности развития России.

В настоящее время сложилось понимание того, что классическая модернизация, как переход от традиционного общества к современному, происходит исключительно на основе копирования пути развития стран Запада и не является для многих других государств эффективным способом достижения экономического ро-
В такой ситуации и перед Россией стоит задача модернизации своих институтов, от успешного решения
Исследование выполнено в рамках гранта Президента РФ для государственной поддержки молодых российских ученых - докторов наук (МД-1493.2020.6) на тему «Ресурс исторической памяти в системе институциональных параметров социально-инвестиционного развития и обеспечения культурной безопасности региона». 
ста. Напротив, ученые заметили, что сегодня «все более очевидным является тот факт, что разнообразие институтов, существующих в современных обществах, причем не только модернизирующихся или переживающих переходный период, но и развитых, и даже высоко развитых, весьма велико» [Durkheim, 1972, 422]. Данная ситуация порождает дискурс о наличии множества моделей модернизации, эффективность которых опирается на культурно-исторические традиции народов, сохранение которых в политических и экономических институтах при использовании новых технологических достижений обеспечивает их социально-экономические успехи.

Достижения многих незападных стран свидетельствуют об успешном сочетании традиционных институтов с рациональным использованием международного опыта. Ярким примером такого симбиоза являются страны Восточной Азии (Япония, Южная Корея, Тайвань, Сингапур) которые сумели синтезировать демократические принципы и конституционный либерализм с особенностями своей политической культуры, включая специфику конфессиональной организации общества...» [Воскресенский, 2014, 121].

Показательным примером успешной модернизации считается опыт Сингапура, который представляет собой город-государство, которое не имея никаких природных ресурсов стало мировым финансовым центром и заняло лидирующие позиции в области высоких технологий. Эксперты утверждают, что основными факторами достижения такого уровня развития страны являются «продуманная инвестиционная политика, ужесточение законодательства, эффективная борьба в процессе модернизации с коррупцией (что особенно актуально для России)» [Ашурова, 2016, 146-146].

В условиях нового витка геополитического противостояния с Западом и затянувшегося социально-экономического кризиса в стране, перед Россией остро стоит задача модернизации, от решения которой во многом будет зависеть ее экономический и политический суверенитет, a, следовательно, национальная безопасность государства.

Сегодня в российском обществе сложился запрос на модернизацию политических институтов, которые в силу своей неэффективности, забюрократизированности, разбалансированности не способствуют улучшению инвестиционного климата и существенно тормозят экономическое развитие общества. В этой связи одним из важных вопросов является влияние фактора исторической памяти на деятельность политической системы страны. Причем это влияние носит двоякий характер: с одной стороны, историческая память обеспечивает духовную интеграцию государства на основе общего понимания прошлого, межпоколенную приемственность и т.п., а с другой стороны, воспроизводит архаические способы управления обществом, не отвечающие совре- менным вызовам, стоящим перед Россией.

В научной литературе понятие «политическая модернизация» отражает процесс качественного обновление политических институтов общества. В современных подходах политическая модернизация непосредственно связана с «реальной активизацией политического участия населения, развитием многопартийности, становлением и развитием открытых плюралистических политических систем» [Абрамов, 2012]. Данный процесс характерен для обществ переходного периода и связан, прежде всего, с изменениями политической системы, которые способны, «обеспечить внедрение инноваций, отвечающих назревшим потребностям жизни общества» [Матвиенко, 2002, 3]. В этом случае речь идет о таких трансформациях в деятельности политических институтов, которые соответствовали бы потребностям экономической и социальной сфер жизни социума.

В тоже время, рассматривая политическую модернизацию как формирование современной политической структуры общества, специалисты считают что «под современными политическими институтами и практиками следует понимать не слепок с политических институтов стран развитой демократии, а те политические институты и практики, которые в наибольшей степени способны обеспечивать адекватное реагирование и приспособление политический системы к изменяющимся условиям, к вызовам современности» [Баранов, 2004].

В связи с этим перед российским обществом остро стоит проблема выбора модели политической модернизации. Сложность решения этой проблемы обусловлена не только самобытностью российских политических институтов, но и их спецификой, проявляющейся в «сочетании собственной цивилизационной основы с рядом черт западного и восточного типов...» [Лебедев, 2010, 291-292]. Такой синкретизм значительно затрудняет выбор модели политической модернизации страны.

Кроме того, в России сам процесс модернизации обладает рядом особенностей. Во-первых, в российском обществе процессы модернизации традиционно носили догоняющий характер. Последний представляет собой такой «путь национального ускорения, когда в результате социального напряжения страна в форсированном порядке пытается повторить этапы развития, пройденные в течение нескольких столетий Западом» [Коровицына, 2000, 9]. В этом плане институциональные трансформации осуществляются преимущественно в результате копирования институтов западного мира.

Специалисты подчеркивают, что «целью «догоняющей» модернизации является преодоление в короткие сроки разрыва между отсталыми и передовыми странами. «Догоняющая» модернизация проводится, как пра- 
вило, авторитарным государством «сверху» жесткими, зачастую деспотическими методами» [Суздалева и Федоров, 2013, 2]. В такой ситуации ключевым субъектом, инициирующим развитие общества, выступает государство, которое посредством насилия и принуждения стремилось преодолеть инерцию социума, внедряя в него инновационные компоненты. По мнению историков, такой способ модернизации общества является исторической традицией России, «в которой все модернизации XVIII$\mathrm{XX}$ вв. осуществлялись «сверху» авторитарной государственной властью» [Земцов, 2011, 65].

Наряду с догоняющей модернизацией, для России свойственна также «частичная» модернизация. Последняя, по мнению ученых, представляет собой процесс формирования инновационных форм политической организации, который «не способствует полной социальной модернизации и сопровождается укреплением традиционных ценностей...» [Лубский и Головко, 2015, 72]. В силу этого его особенностью становится незавершенность, которая является результатом сопротивления традиционных институтов общества новым организационным структурам. Такая ситуация характеризуется коллизией традиционности и инновационности, возникающей в институциональной среде, неразрешенность которой ведет общество к стагнации.

Кроме того, ученые отмечают, что «вторжение готовых образцов и институтов и практики модернизированного мира в социально-исторический контекст общества, еще не готового к модернизации, может приводить к конфликтным ситуациям и даже к параличу модернизации» [Докучаев, 2013, 90]. В результате в обществе складывается институциональный коллапс, тормозящий дальнейшее его развитие.

В сфере политического управления данный коллапс проявляется в том, что структуры управления различными сферами общества, по большому счету, не выполняют свои функций и зачастую не подчиняются формальным правовым актам, решение проблем осуществляется исключительно на основе неформальных отношений, то есть посредством «ручного управления», а именно телефонного права, указаний вышестоящего начальства и т.п.

Очевидно, что столкновение традиции и инновации неизбежно сопровождается гибридизацией институциональной среды, «когда новые институты и социальные практики сосуществуют с аналогами, оставшимися от прошлого. Создается слоевой комплекс институтов, базирующихся на соперничающих нормативных и организационных принципах. В итоге формируется специфичный для транзитных обществ неконгруэнтный институциональный дизайн, когда институты не представляют целостный политико-административный порядок и соз- дают ригидную институциональную среду, не способную адаптироваться к общественным изменениям без кризисов и внутреннего разрушения» [Explaining Institutional Change: Ambiguity, Agency, and Power, 2010].

Анализ процессов модернизации в России позволяет заключить, что ее спецификой является наличие ситуаций одновременного присутствия как либеральных, так и авторитарных методов управления страной: «первые методы обычно не завершались и были малоэффективны, а вторые - были квазиэффективными, так как давали быстрый результат, но затем приводили к откату» [Ашурова, 2016, 145].

Результатом такого управления стало формирование в России общества мобилизационного типа, для которого в условиях угрозы или кризиса характерно использование кратковременных чрезвычайных мер для решения критических ситуаций. Именно мобилизационный тип общества лег в основу и стал определять политический архетип страны, постоянно воспроизводящийся на различных исторических этапах развития российской государственности. По мнению ученых, именно мобилизационный характер российского общества «актуализирует этатистский вариант обновления, завершающийся скатыванием в «проторенную колею» мобилизационно-модернизационного развития [Лубский и Головко, $2015,72]$. Очевидно, что в этом случае сильное влияние играет историческая память, которая хранит данный политический архетип и передает новым поколениям определенную модель политической культуры и типовые образцы политического поведения. Основными чертами российской политической культуры являются авторитаризм власти, правовой нигилизм, патернализм, этатизм. Сохранение их в исторической памяти народа определяет постоянно воспроизводящуюся колею мобилизационно-модернизационного развития общества. В этом плане, историческая память выступает одним из компонентов институциональной матрицы, который консервирует и определяет вектор развития основных институтов общества.

В научной литературе под институциональной матрицей понимается «устойчивая, исторически сложившаяся система базовых институтов, регулирующих взаимосвязанное функционирование основных общественных сфер - экономической, политической и идеологической» [Кирдина, 2014, 67]. Консервируя и воспроизводя авторитарную модель политического управления обществом, историческая память нередко блокирует развитие иных более эффективных способов управления, адекватных реалиям современного мира.

В условиях полиэтничности российского социума модернизация политических институтов общества сталкивается с сохранением во многих регионах страны традиционных форм управления, опираю- 
щихся на религиозный фактор и клановость в органах местной власти.

Известный специалист в области формирования местных социально-политических сообществ П. Бурдье отмечает, что «важными условиями формирования местных социально-политических образований, наряду с территорией, выступают их ментальные предпосылки, представления, мнения, образ мыслей, суждения, осознание гражданами своих ценностей, целей, интересов» [Бурдье, 1993, 37]. Эти ментальные установки заключены в структуру исторической памяти и определяют специфику социально-политических отношений в обществе.

Как показывает практика, у многих народов северокавказского региона институтами регулирования социально-правовых отношений до сих пор выступают адат и шариат. Исследователи отмечают, что «правовые обычаи, в том числе у чеченцев и ингушей, называемые «адатами», играли и продолжают играть важную роль в их обыденной жизни. Адат в переводе с арабского означает «обычай». Он регулирует вопросы в самых разнообразных сферах и отражает реалии правовой жизни, не обозначенные в шариате» [Ахмадеев, 2017, 4]. Кроме того, адати шариат выступают не только традиционными институтами, регулирующими общественные отношения, но и основой этнорелигиозной идентичности народов. Очевидно, что возрождение адата и шариата обусловлено распространением ислама и его влиянием на политико-правовые институты мусульман, проживающих в северокавказском регионе.

На этом основании ученые призывают учитывать в политическом управлении региона религиозные и правовые традиции, которые закреплены в исторической памяти народов Северного Кавказа. Более того, некоторые исследователи полагают, что «для региона с его многочисленным мусульманским населением, возможно, следует провести кодификацию и «модернизированного» мусульманского права, которое должно при наличии разумных ограничений учитываться при составлении местных и федеральных законов» [Саидов, 2013, 42].

Таким образом, в процессах политической модернизации следует принимать во внимание консерватизм норм и принципов мусульманского права и адата, их присутствие в исторической памяти народов, а также их влияние на функционирование политических институтов в регионе.

Еще одним фактором, определяющим специфику политического управления на Северном Кавказе, является клановость, характерная для некоторых районов региона. По мнению специалистов, проникновение клановости в экономическую и политическую сферы общества свидетельствует о наличии демодернизационных про- цессов, проявляющихся в возрождении архаических социальных институтов, в частности тейповых, джамаатских и других патриархальных связей. В этом плане архаизация представляет собой процесс восстановления традиционных социальных практик организации коллективной жизни, которые хранятся в исторической памяти народов и актуализируются на современном этапе, указывая, тем самым, на наличие в обществе институционального кризиса.

В тоже время, следует отметить, что сама клановость как система управления экономическими и политическими процессами в национальных республиках России претерпела определенные трансформации: если изначально она строилась исключительно на основе кровнородственных отношений, этнической принадлежности, то сегодня «основой функционирования и благополучия правящего клана является принцип верности общим интересам и безоговорочной преданности верхушке. Кланы почти везде интернациональные, в них принимают только тех, в преданности кого абсолютно уверены. В таких кланах есть бизнесмены, чиновники и даже сотрудники правоохранительных органов и спецслужб, но и представители криминала» [Пеньковский, 2012, 96].

Стоит сказать, что сохранение клановости на Северном Кавказе связано не только с исторической практикой организации общественной жизни, но и со спецификой политической культуры народов региона, для которой свойственна «приверженность групповым, коллективистским и иерархическим нормам и ценностям» [Ханалиев, 2013, 181]. Ориентация на авторитаризм, клиентилизм, этатизм, определяет модель политического управления во многих национальных республиках Российской Федерации.

Очевидно, что такая ситуация серьезно осложняет современную политическую жизнь в республиках Северного Кавказа, негативно влияя не только на социально-экономическое состояние территорий, но и на безопасность региона в целом. Надо отметить, что именно клановая структура власти привела к образованию монополии на экономические ресурсы, установила приоритет неформальных механизмов принятия политикоуправленческих решений вопреки федеральным и региональным законам.

Серьезную угрозу безопасности региона создает перманентно идущая борьба кланов за политические и экономические ресурсы. Причем, эксперты отмечают, что «зачастую конфликты кланов накладываются на заинтересованность этих сообществ в лице местных властей на поддержание «управляемой нестабильности» с целью сохранить и расширить объемы трансфертов из федерального центра» [Липина, 2020]. Тем самым, поддержание нестабильности является одним из способов 
обогащения политической элиты республик. Отчасти именно этим можно объяснить, что во многих республиках, в частности Ингушетии, Дагестана, Карачаево-Черкесии, власть нередко демонстрировало свою полную несостоятельность в решении социально-экономических проблем своих территорий, а также в борьбе с террористическим и криминальным группировкам.

Более того, представители правоохранительных органов, по мнению специалистов, «предпочитают действовать не в интересах закона, а исхода исходя из своих личных и клановых интересов» [Ханалиев, 2013, 182]. Об этом свидетельствует очень высокий уровень коррупции во властных структурах национальных республик, который указывает на глубокий кризис политических институтов северокавказского региона. Очевидно, что коррумпированная клановая система власти не стремится осуществлять политическую модернизацию общества и менять патриархальный уклад жизни, что является серьезным препятствием для социально-инвестиционного развития региона.

Сложившаяся клановая структура во многих республиках региона вовлекает в свою сеть практически все население, поскольку концентрация ресурсов в руках нескольких кланов не способствует честной конкуренции и не оставляет возможности для осуществления самостоятельной экономической активности. Поэтому, в условиях отсутствия равных возможностей, неразвитости институтов гражданского общества для многих людей включенность в клановые и клиентские сети является единственной возможностью выживания.

Такая ситуация в регионе свидетельствует о низком потенциале его социально-инвестиционного развития. Поэтому перед федеральным центром стоит задача ликвидации клановой системы, которая не создает институциональную среду для дальнейшего развития общества, а наоборот, тормозит работу демократических механизмов, позволяющих функционировать институтам гражданского общества в сложном полиэтничном регионе.

Однако важно учесть, что формирование новых политических институтов, способных обеспечить экономический рост и поднять уровень жизни населения в республиках Северного Кавказа, может осуществляться только эволюционным путем, поскольку требует много усилий и времени. Кроме того, политическая модернизация возможна исключительно на основе формирования новой политической культуры, связанной с принятием правил игры политической демократии. Очевидно, что сложности ее формирования обусловлены влиянием исторической памяти, политические архетипы которой воспроизводят архаические способы организации политических отношений в обществе.

Огромную роль в политических процессах регионального социума играет этнический фактор, пронизывающий все сферы общественной жизни. Так, по мнению Р. М. Эмирова, даже политические предпочтения людей в большей степени «определяются их принадлежностью к определенной этнонациональной группе, тухуму, языку, клану, местности. Здесь нет просто абстрактных, статистических избирателей, а есть избиратели-лезгины, избиратели-кумыки, избиратели-аварцы и т. д. Любые проблемы социального, экономического, образовательного или иного характера так или иначе связаны с этнонациональным вопросом, от степени решенности (или нерешенности) которого зависят основные векторы развития региона» [Эмиров, 2013]. Без учета этнического фактора развитие в регионе политических институтов невозможно.

В настоящее время в научном и политическом дискурсе наблюдается отказ от одномерных моделей модернизации, которые ориентированы на исключительно линейный путь развития социума, предполагающий механическое копирование западных институтов политической демократии. Сегодня сложилось понимание того, что процессы политической модернизации должны ориентироваться на культурно-национальные традиции народов, необходимо использовать их потенциал в интеграции и мобилизации общества для дальнейшего развития, а не скатывания в архаику, не способствующую решению социально-экономических проблем и представляющую латентную угрозу безопасности региона.

Исследователи правомерно отмечают, что проблему клановости, клиентелизма и коррупции невозможно решить исключительно административными методами, для ее окончательного решения «потребуются совместные усилия гражданского общества, государственной власти всех уровней, интеллектуального сообщества, всех народов Северо-Кавказского Федерального округа [Саркарова, 2016].

Для создания благоприятного социально-инвестиционного климата в регионе необходимы современные политические институты, деятельность которых направлена выявление причин кризисного состояния социума, определение стратегии социально-экономического развития территорий, поиск ресурсов, способных обеспечить внедрение инноваций, отвечающих потребностям жизни общества. Очевидно, что решение проблемы формирования эффективных политических институтов носит исключительно комплексный характер и не может быть оторвано от развития духовных институтов общества, таких как образование, наука, культура в целом. 


\section{ЛИТЕРАТУРА}

1. Durkheim E. Selected Writings // Ed. A. Giddens. Cambridge: Cambridge University Press, 1972.

2. Explaining Institutional Change: Ambiguity, Agency, and Power / eds.: J. Mahoney, K. Thelen. New York: Cambridge University Press, 2010.

3. Абрамов Р.Н. Модернизация политической системы России // Общественные науки. Политика и право. 2012. № 1 (21).

4. Ахмадеев К.Н. Базовые характеристики традиционного чеченского общества: хозяйственно-экономический и политико-правовой аспекты // 0бщество: политика, экономика, право. 2017. № 9.

5. Ашурова М.А Догоняющая модернизация национальной экономики // Вестник университета. 2016. № 2.

6. Баранов Н.А. Политические отношения и политический процесс в современной России. СПб.: БГТУ, 2004.

7. Бурдье П. Социология политики. М.: Socio-Logos, 1993.

8. Воскресенский А.Д. Эволюция политической системы и политическая модернизация КНР: проблемы и преимущества «китайской модели» // Сравнительная политика. 2014. № 1 (14).

9. Докучаева И.Г. Политическая модернизация // Россия в прошлом и настоящем. Внутренняя и внешняя политика России в XX — начале XXI вB. Новосибирск: Изд-во «НИНХ», 2013.

10. Земцов Б.Н. Специфика российских реформ (историческая ретроспектива) // Модернизация как условие развития современной России.М.: МЭСИ, 2011.

11. Кирдина С.Г. Институциональные матрицы и развитие России: введение в Х-Ү-теорию. Издание 3-е, переработанное, расширенное и иллюстрированное. СПб.: Нестор-История, 2014.

12. Коровицына Н.В. Регион «догоняющей «модернизации: коммунистический и либерально-демократический опыт // Центральная Европа в поисках новой региональной идентичности. М., 2000.

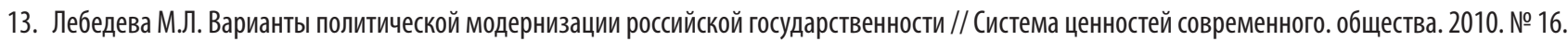

14. Липина С.А. Развитие ситуации на Северном Кавказе: интервью редакции электронного издания «Информационно-аналитический портал «VIPERSON». [Электронный ресурс] // www.viperson.ru (дата обращения 21.06.2020).

15. Лубский Р.А., Головко В.А. Мобилизационно-модернизационный тип российской государственности // Философия права. 2015. № 6 (73).

16. Матвеенко Ю.И. Политическая модернизация как фактор консолидации современного российского общества. Автореферат дисс. докт. полит. наук. M. 2002. C.3.

17. Пеньковской Д.Д. Современные политические элиты республик Северного Кавказа // Знание. Понимание. Умение. 2012. № 2.

18. Саидов А.А. Исламский фактор местного самоуправления в демократизации политических систем республик Северного Кавказа // Исламоведение. 2013. № 4.

19. Саркарова Дж.С. 0 клановости в политической жизни республик Северного Кавказа // Вопросы политологии. 2016. № 4 (24).

20. Суздалева Т.Р., Федоров К.В. «Догоняющая» модель модернизации: теоретические и историографические аспекты // Гуманитарный вестник. 2013. № 5 (7).

21. Ханалиев Н.У. Некоторые особенности политических режимов национальных республик Северного Кавказа // Власть. 2013. № 11.

22. Эмиров Р.М. Геополитические приоритеты национальной безопасности Российской Федерации на Северном Кавказе. Автореф. дис. ... канд. полит. наук. M., 2013.

( ) Воденко Константин Викторович (vodenkok@mail.ru), Лабадзе Олеся Евгеньевна (efimowa.olesya@yandex.ru), Тихоновскова Мария Петровна (tikhonovskova.maria@yandex.ru).

Журнал «Современная наука: актуальные проблемы теории и практики» 